\title{
Validation of Customer Perspectives in the Context of NGO's Performance Evaluation in Kenya
}

\author{
Nasline Akinyi Ouko, ${ }^{1,}$, Charles Rambo ${ }^{1}$, Paul Odundo ${ }^{2}$, Raphael Nyonje ${ }^{2}$, David Omondi Okeyo ${ }^{3}$ \\ ${ }^{1}$ Departmentof Extra Mural Studies, the University of Nairobi, Nairobi, Kenya \\ ${ }^{2}$ Department of Education Communication Technology, the University of Nairobi, Nairobi, Kenya \\ ${ }^{3}$ School of Public Health and Community Development, Maseno University, Kisumu, Kenya
}

Email address:

naslin.omos@gmail.com (N. A. Ouko)

${ }^{*}$ Corresponding author

\section{To cite this article:}

Nasline Akinyi Ouko, Charles Rambo, Paul Odundo, Raphael Nyonje, David Omondi Okeyo. Validation of Customer Perspectives in the Context of NGO's Performance Evaluation in Kenya. International Journal of Economics, Finance and Management Sciences. Vol. 4, No. 4, 2016, pp. 199-204. doi: 10.11648/j.ijefm.20160404.15

Received: June 17, 2016; Accepted: July 4, 2016; Published: July 28, 2016

\begin{abstract}
Customer segments are key performance gauge for effective and efficient Non-Governmental Organizations. There seems to be little assessment of customer related components in the NGO's performance measurement mix despite many donor-funded projects implemented in Nyanza region in Kenya. This study explored key customer perspectives guided by one of the Balanced Score Card model pillars in the NGO performance measurement concept. The study engaged 64 top managers of NGOs dealing in livelihood issues within Nyanza region. Structured questionnaire was used to explore critical areas of the customer perspective as performance indicators. Data analysis was based on descriptive statistics at the preliminary stage and hierarchical regression based on principal axis factoring. The results revealed four categories of customer perspectives in the competition. The leading category accounted for $17.25 \%$ of customer perspective performance characterized by presence of service charter, objectives related to customer/beneficiary services and existence of relevant ICT/information material. The second category accounted for $14.48 \%$ of the variance and was characterized by engagement in activities that respond to immediate beneficiary needs. The third category accounted for $13.11 \%$ and was characterized by the value of honesty, courtesy, transparency and beneficiary accountability. The last category of customer perspective accounted for $7.61 \%$ of the variance and was characterized by regular execution of beneficiary satisfaction survey. In conclusion, the study established that key customer perspectives in the NGOs performance measurement area the presence of service charter, clear objectives related to customer/beneficiary services and existence of relevant ICT/information materials. It therefore recommends putting more emphasis in regular beneficiary satisfaction surveys as this area is more likely to be ignored in the performance measurement.
\end{abstract}

Keywords: Customer Perspective, Performance, Evaluation, Ngo, Kenya

\section{Introduction}

NGOs serve three 'customers' segments including donors, constituents and employees. The customer perspective of the Balanced Scorecard (BSC) has to incorporate performance effectiveness as perceived by various customer segments. Based on the assessment information gained from the customer perspective, the organization can easily identify critical performance measures in the other three perspectives (internal processes, learning and growth and financial). Monitoring customer processes through the BSC helps non- profits collect information about customer's perceived value, service quality, delivery time and costs, and customer's satisfaction. Thus, they will be able to align their strategic plans to the achievement of higher customer intimacy, superior service quality perception and operational Excellency [1].

Hartnett and Matan [2] supports the foregoing argument by asserting that this perspective is about the donor, volunteers or clientele (users of the services) experience, which is found by measuring satisfaction and retention as well as assessing the non-profit's market in its niche. Management philosophy has shown an increasing realization of the importance of 
customer focus and customer satisfaction. These are leading indicators which attempts to indicate that if the customers are not satisfied, they will eventually find other suppliers that will meet their needs. Poor performance from this perspective is thus a leading indicator of future decline, even though the current picture may look good [1].

Niven [3] concurs that being able to satisfy customer needs is fundamental to all corporations and to achieve positive financial results (both in the short and long term), many organizations gear themselves towards their customers and also include them in their mission. Hartnett and Matan [2], assert that every NGO should measure the attitude of its strongest and most loyal customers (supporters) to gain the most for the organizations. Keeping donors and volunteers engaged and enthusiastic and identifying ways to do that through the BSC provides an incredible advantage for any organization. Hassan [4] further argues that the determinants of NGOs' success are the relevance of services provided to social needs, which is a sole assessment of customers. This school of thought emphasizes the importance of customer needs satisfaction as a performance area of NGO's.

The findings of Carman and Fredrick's [5] revealed about $67 \%$ of NGOs who collect data on participant satisfaction on regular basis. These arguments NGOs should therefore put in place mechanisms that will enable them get feedback on customer satisfaction for them to realize their missions. This is because customer satisfaction will also enable them access more donor funding which would ensure their continued survival. This paper therefore explores and validates key elements of customer perspective from the Balanced Score Card framework within the context of NGO's performance within Nyanza region, Kenya.

\section{Materials and Methods}

\subsection{Research Design}

This study adopted a cross-sectional analytical study design where data was collected once within a predetermined period of one month and analyzed. This design was appropriate because it did not allow for any form of manipulation of variables and it helped in assessing relationship between variables as they were during the period of assessment.

\subsection{Target Population and Sampling}

The study population was drawn from NGOs operating in Kisumu County and implementing livelihood project. This county is located in Nyanza and borders Lake Victoria to the West, Siaya, Vihiga and Nandi counties to the North, Kericho County to the East and Homa Bay County to the South. The region covers an area of $2,086 \mathrm{Km}^{2}$ and has a population of 968,909 individuals. The study established a sampling frame (population) made up of 3 top managers including programme/project managers, monitoring and evaluation, and accountant of Non-Governmental Organizations. Since the eligible number of NGOs was 30 , the target population for this study was 90 managers. About 64 tops managers were reached in the study. This implies that response rate was $74 \%$ which warranted a test for sample size adequacy for each indicator item.

\subsection{Research Instruments}

Data was collected using semi-structured questionnaires. The questionnaires were structured into sections thematically organized to capture the key elements in customer perspectives theoretically drawn from the BSC concept. The customer perspective had a set of item measures with a focus on service charter, objectives related to customers, ICT information materials, achievement of customer objectives, stakeholder participation, suggestion box, honesty courtesy transparency, response time, customer survey and stakeholder participation.

\subsection{Pilot Testing}

A pilot study was carried out among $15 \%$ of the sample size amounting to 14 eligible respondents. These respondents were part of the selected sample to be used in the study so they were excluded from the study sample. The pilot study adopted the same procedures and sampling technique adopted in the main study. After pilot testing data was analyzed, the resultant product was used to provide suggestions on how the research instruments could be reviewed and revised to become suitable for the study. This was done in order to test for the validity and reliability of the research instruments. Construct validity was assessed by evaluating the opinion of the respondent against each score using principle axis factoring. The researcher used simple, clear and non-ambiguous language in the instruments. The supervisor reviewed the tools to see if they answer the objectives and research questions. After the exercise of data collection, all the questionnaires were verified to check if all the questions were well answered to the end to ensure validity of collected data.

The research instrument was administered to the $15 \%$ of the respondents and data obtained split into two sub sets (the sets had odd numbers and even numbers). All even numbered items and odd numbered responses in the pilot study were computed separately. Reliability test statistics based on Cronbach alpha revealed coefficients greater than 0.7 across all perspective measures. This indicated an acceptable instrument.

\subsection{Data Collection Procedure}

The 64 questionnaires were administered by the researcher to the respective managers in their offices upon booking of appointments.

\subsection{Data Analysis Techniques}

Data was analyzed using descriptive statistics where quantitative and qualitative approaches were used. Quantitative data analysis was done by objectives. Data collected using semi-structured questionnaires was entered into Statistical Package for Social Sciences (SPSS) version 19.0 spreadsheet and cleaned. Descriptive statistics were run to establish the accuracy of entry of scores by assessing range, mean, standard deviation and normality of data. Inferential statistics mainly 
hierarchical regression was used to assess the contribution of each of the perspectives as performance measurement measures by objectives. In this analysis all the item measures for the customer perspective were subjected to descriptive analysis followed by factor analysis and finally linear regression to show the most widely practiced aspects of the key measures of perspectives. All the data were analyzed at $95 \%$ level of significance and the degrees of freedom.

\subsection{Ethical Consideration}

Before the study was conducted, the proposal was presented to the University of Nairobi for approval. Relevant local authorities were informed of the study for clearance to access the Non-Governmental Organizations. The researcher obtained a research permit from the National Council of Science and Technology headquarters to collect data from Non-Governmental Organizations (NGOs) in Kisumu County. Verbal consent was sought from the respondents before they participated in the study. The respondents who chose to participate were assured that the information they gave was confidential and would not be used for any other purpose except for this study. Every questionnaire remained anonymous, as the respondents were only assigned identity numbers instead of writing their names.

\section{Results}

The customer perspective had 10 items measures including presence of a service charter, presence of objectives related to customer service, existing relevant ICT/materials, existing suggestion box for customers, values of honesty, courtesy and transparency, definite response duration for customer feedback, stakeholder participation in design, implementation and monitoring of activities, regular customer satisfaction surveys, activities that respond to immediate needs of the customers, and finally ensuring that customer related objectives are achieved. These item measures were put to test for their applicability in the Non-Governmental Organizations (NGO) working in Kisumu County. Descriptive statistics were run for all the items to assess for the accuracy of entry of data, mean score for each item and normality. Table 1 shows the means recorded across all item measures.

Table 1. Mean customer perspective item measures.

\begin{tabular}{|c|c|c|c|c|c|}
\hline Customer perspective item measures $(n=64)$ & Min & Max & Mean & SD & Skewness \\
\hline Presence of Service charter. & 1.00 & 5.00 & 4.14 & 1.05 & -1.387 \\
\hline Presence of objectives related to customer service. & 1.00 & 5.00 & 4.45 & .92 & -2.159 \\
\hline Existing relevant ICT/information materials. $\emptyset$ & 1.00 & 5.00 & 4.40 & .95 & -2.038 \\
\hline Existing suggestion box for customer & 1.00 & 5.00 & 3.38 & 1.54 & -.341 \\
\hline Values of honesty, courtesy and transparent. $\uparrow$ & 2.00 & 5.00 & 4.64 & .68 & -2.290 \\
\hline Definite response duration for customer feedback. & 1.00 & 5.00 & 3.96 & .89 & -.634 \\
\hline Stakeholder participation in design, implementation and monitoring of activities. & 2.00 & 5.00 & 4.55 & .71 & -1.537 \\
\hline Regular customer satisfaction surveys. & 1.00 & 5.00 & 3.80 & 1.23 & -.899 \\
\hline Activities that respond to immediate needs of the customers. & 1.00 & 5.00 & 4.47 & .89 & -1.783 \\
\hline Ensuring that customer related objectives are achieved. & 2.00 & 5.00 & 4.53 & .71 & -1.475 \\
\hline
\end{tabular}

Table 1 shows that high means above average were recorded across all item measures with three items, existing suggestion box for customers, stakeholder participation in design, implementation and monitoring activities and lastly regular customer satisfaction surveys registering the lowest means. All the item measures were normally distributed except for the case of presence of objectives related to customer service, existing relevant ICT / information materials and definite response duration for customer feedback.

Further analysis was conducted to identify those items that were strongly practised by the organizations. All the 10 item measures for customer perspectives were first tested for sample size adequacy using Kaiser Meyer Olkins (KMO) and Bartlett's test of sphericity. The results indicated that the sample size was adequate for each item $(\mathrm{KMO}=.705$; $\left.\chi^{2}=163.037 ; \mathrm{df}=45 ; \mathrm{p}<0.05\right)$ leading to factor analysis. These item measures were further subjected to extraction to determine which factors could be extracted. These have been summarized in table 2 .

Table 2. Total variance explained by customer perspective factors

\begin{tabular}{|c|c|c|c|c|c|c|}
\hline \multirow{2}{*}{ Factor } & \multicolumn{3}{|c|}{ Initial Eigen values } & \multicolumn{3}{|c|}{ Rotation Sums of Squared Loadings } \\
\hline & Total & $\%$ of Variance & Cumulative\% & Total & $\%$ of Variance & Cumulative\% \\
\hline 1 & 3.072 & 30.72 & 30.72 & 1.726 & 17.258 & 17.258 \\
\hline 2 & 1.693 & 16.93 & 47.65 & 1.448 & 14.476 & 31.733 \\
\hline 3 & 1.230 & 12.30 & 59.96 & 1.311 & 13.111 & 44.844 \\
\hline 4 & 1.009 & 10.09 & 70.045 & .762 & 7.619 & 52.463 \\
\hline 5 & .926 & 9.26 & 79.30 & & & \\
\hline 6 & .551 & 5.51 & 84.81 & & & \\
\hline 7 & .504 & 5.04 & 89.85 & & & \\
\hline 8 & .387 & 3.87 & 93.72 & & & \\
\hline 9 & .348 & 3.48 & 97.20 & & & \\
\hline 10 & .280 & 2.80 & 100.00 & & & \\
\hline
\end{tabular}


Table 3 shows the number of possible item measures that could be extracted from the customer perspective measures. About 10 possible factors could be extracted, however based on the standard Eigen values set at 1; only 4 factor clusters were valid. The overall variance for the customer perspective item measures accounted for by the factors was $52.46 \%$. These findings confirm that the information gained from the customer perspective can be used by an organization to identify critical measures in other perspectives (internal processes, learning and growth and financial). Factor 1 registered the highest variance of $17.25 \%$ followed by Factor $2(14.48 \%)$ then Factor $3(13.11 \%)$ and finally Factor 4 (7.619\%).

The subsequent analysis displayed the four Factors in a rotated factor matrix revealing three factor clusters, and a single factor item as indicated in table 3

Table 3. Rotated Factor Matrix for Customer Perspective.

\begin{tabular}{|c|c|c|c|c|}
\hline \multirow{2}{*}{ Customer perspective item measures $(n=64)$} & \multicolumn{4}{|c|}{ Customer Perspective Factor Loadings } \\
\hline & 1 & 2 & 3 & 4 \\
\hline Presence of Service charter. & .659 & & & \\
\hline Presence of objectives related to customer service. & .793 & & & \\
\hline Existing relevant ICT/information materials & .663 & & & \\
\hline \multicolumn{5}{|l|}{ Existing suggestion box for customer } \\
\hline Values of honesty, courtesy and transparency. & & & .828 & \\
\hline \multicolumn{5}{|l|}{ Definite response duration for customer feedback. } \\
\hline Stakeholder participation in design, implementation and monitoring of activities. & & & .633 & \\
\hline Regular customer satisfaction surveys. & & & & .727 \\
\hline Activities that respond to immediate needs of the customers. & & .719 & & \\
\hline Variance explained $(\%)$ & 17.25 & 14.48 & 13.11 & 7.619 \\
\hline
\end{tabular}

Table 3 shows that when small coefficients were suppressed to below 40 percent in the Principal Axis Factoring based on varimax rotation, only those items displayed in the table were extracted as key measures of the customer perspective. Only 8 out of the 10 item measures were extracted. These item measures included presence of a service charter, objectives related to customer service, existing relevant ICT/ information materials, values of honesty, courtesy and transparency, stakeholder participation in design, implementation and monitoring of activities, regular customer satisfaction surveys, activities that respond to immediate needs of the customers, finally ensuring that customer related objectives are achieved. It emerged that two item measures were not extracted. This included presence of a suggestion box and definite response duration for customer feedback. This implies that these item measures that were not extracted are not widely practiced in NGOs in Kisumu County.

Further analysis was done to show the magnitude of predictors of Factor loading 1. The model output revealed that the three items including the presence of a well stated service charter, a well stated objectives related to customer service, and availing relevant ICT/information materials significantly explained up to $86.7 \%$ of the total variance in customer perspective category-1 $(\mathrm{R}=0.867, \quad \mathrm{~F}=137.92$, $\mathrm{p}<0.05)$. Table 4 summarizes these factors. It revealed that the presence of well stated objectives related to customer service was the best predictor of factor $1(\beta=0.523, t=8.61$, $\mathrm{p}<0.05)$. This was followed by the presence of a well stated service charter $(\beta=0.303, t=5.316, p<0.05)$ and availability of relevant ICT/information materials to customers $(\beta=0.289$, $\mathrm{t}=5.178, \mathrm{p}<0.05)$. This clearly indicates that NGOs have implemented measures that are tailored toward customer needs. However, due to normality violation for well stated objectives related to customer service and availing relevant ICT/information materials, caution should be taken when drawing conclusions towards the significance put on each item.

Table 4. Regression Analysis of customer perspective category -1.

\begin{tabular}{|c|c|c|c|c|c|c|}
\hline \multirow{2}{*}{\multicolumn{2}{|c|}{ Model (Y) }} & \multicolumn{2}{|c|}{$\begin{array}{l}\text { Unstandardized } \\
\text { Coefficients }\end{array}$} & \multirow{2}{*}{$\begin{array}{l}\text { Standardized } \\
\text { Coefficients } \\
\text { Beta } \\
\end{array}$} & \multirow[t]{2}{*}{$\mathbf{t}$} & \multirow[t]{2}{*}{ Sig. } \\
\hline & & B & Std. Error & & & \\
\hline \multirow{4}{*}{1} & (Constant) & -5.648 & .285 & & -19.791 & .000 \\
\hline & Presence of Service charter. & .323 & .061 & .303 & 5.316 & .000 \\
\hline & Presence of objectives related to customer service. & .633 & .074 & .523 & 8.610 & .000 \\
\hline & Availability and relevant ICT/information materials & .339 & .065 & .289 & 5.178 & .000 \\
\hline \multirow{3}{*}{2} & (Constant) & -7.062 & .290 & & -24.322 & .000 \\
\hline & Activities that respond to immediate needs of the customers. & .553 & .062 & .430 & 8.941 & .000 \\
\hline & Ensuring that customer related objectives are achieved. & 1.013 & .077 & .631 & 13.110 & .000 \\
\hline \multirow{3}{*}{3} & (Constant) & -7.830 & .445 & & -17.593 & .000 \\
\hline & Values of honesty, courtesy and transparency & 1.247 & 107 & .728 & 11.618 & .000 \\
\hline & Stakeholder participation in design, implementation and monitoring of activities & .449 & .102 & .276 & 4.409 & .000 \\
\hline \multirow{2}{*}{4} & (Constant) & -3.279 & .274 & & -11.988 & .000 \\
\hline & The organization conducts regular customer satisfaction surveys. & .864 & .069 & .848 & 12.599 & .000 \\
\hline
\end{tabular}


A similar analysis for Factor loading 2 was done using regression to display the strength of prediction of the organization activities that respond to immediate needs of the customers as well as ensuring that customer related objectives are achieved. The two customer perspective category- 2 measures significantly accounted for $90.7 \%$ of the variance $(\mathrm{R}=0.907, \mathrm{~F}=308.54, \mathrm{P}<0.05)$. The most powerful predictor of customer perspective category -2 was ensuring that customer related objectives are achieved $(\beta=0.631$, $\mathrm{t}=13.110, \mathrm{p}<0.05)$ followed by immediate response to the needs of the customer $(\beta=0.43, \mathrm{t}=8.941, \mathrm{p}<0.05)$. This implies that organizations have put in place mechanisms that ensures that customer related objectives are achieved and those that respond to immediate response to the needs of customers are also put in place.

Customer perspective category-3 (Factor loading 3) also had two measures which were further tested as valid predictors in a linear regression as in the case of Factor loadings 1 and 2. The two customer perspective category-3 measures significantly accounted for $83.6 \%$ of the variance $(\mathrm{R}=0.836, \mathrm{~F}=161.47, \mathrm{P}<$ 0.05). The most powerful predictor of customer perspective category -3 was values of honesty, courtesy and transparency $(\beta=1.247, \mathrm{t}=11.618, \mathrm{p}<0.05)$ followed by stakeholder participation in design, implementation and monitoring activities $(\beta=0.449, \mathrm{t}=4.409, \mathrm{p}<0.05)$. However, value of honesty also displayed violation of normality assumptions reflecting cautious attempt make conclusive significance contribution. This implies that the NGOs prefer to put in place mechanisms that ensure that the customers are involved in the projects for successful implementation of projects.

A similar analysis for customer perspective category-4 (Factor 4) which had a single item measure was done using linear regression to display the strength of prediction. The single customer perspective category-4 measure, the organization conducts regular customer satisfaction surveys significantly accounted for $71.5 \%$ of the variance $(\mathrm{R}=0.715$, $\mathrm{F}=158.73, \quad \mathrm{P}<0.05)$. An item characterized by "an organizations conducting regular customer satisfaction survey" was a powerful predictor of customer perspective category -4 $(\beta=0.848, \mathrm{t}=12.60, \mathrm{p}<0.05)$. This implies that the NGOs in Kisumu County conduct regular customer satisfaction surveys.

\section{Discussion}

Based on the fact that customer group was traditionally understood as organizations that buy or use the organization's products [6] and therefore critical in the performance evaluation, this study had explored the validity of customer perspective in NGO's performance within the Balanced Score Card framework. The study identified Presence of Service charter, Presence of objectives related to customer service, Existing relevant ICT/information materials, Values of honesty, courtesy and transparency, Stakeholder participation in design, implementation and monitoring of activities, Regular customer satisfaction surveys, Activities that respond to immediate needs of the customers, and ensuring that customer related objectives are achieved as critical customer perspective within the NGO service delivery. Suggestion box was somehow ruled out as a critical factor in this indicator mix.

Looking at the service charter as a key indicator for customer related performance measure, it appears that some authors reaffirm its critical position in performance of an organization. A study that focused on a link between service charter and risks constraining incentives within banks indicated that service charter evidently improves performance of business organizations [7]. This outcome is shared by a study that focused on service charter in relation to trust in government operations whereby in the government of Spain there appeared to be a significant shift from legal tradition of performance to meeting citizens' needs making government more accessible, transparent and open to public [8]. These previous arguments identify service charter as a key component approved for NGOs as a recognizable measure of performance from the customer perspective.

Organizations should set objectives that are related to customer service so as to meet customer needs. This is supported by the study where presence of objectives related to customer service was extracted as one of items in factor loading 1 which a significant indicator for customer related performance measure. This outcome receives support from a perspective where organizations have been seen to set specific goals which are positively related to planning, quality and organizational performance [9]. A similar line of thinking was shared by Smith and Locke [10] who found that goals and task strategies were related to task performance and gave an assurance of future performance. This concept finds its place within the NGO performance measurement where NGO's are expected to set achievable objectives related to the constituents they serve.

Availability of relevant ICT/information materials is important for performance and a good measure of performance among the NGOs in Kenya. This attribute is shared by some authors where ICT adoption had a significant positive relationship with hotel performance. This performance is more on operational productivity than customer satisfaction [11] and had a strong impact on the improvement of the external and internal communication suggesting the need to align ICT investment with organizational processes [12]. It therefore implies that ICT would be more relevant for the implementers of projects than beneficiaries in the context of an NGO. However, it is important to note that the efficiency of implementers translates to benefits to primary target groups.

NGOs operate in environments with limited resources and the global environment for the NGOs continues to change in the context of accountability. Majority of donor agencies want NGOs held accountable for funds they receive and this requires strong accountability demonstrated by core values. Values of honesty, courtesy and transparency; stakeholder participation in design, implementation and monitoring activities emerged as powerful predictor of customer 
perspective. Similarly, Ignatius [13] in his study on Fostering Accountability in Zimbabwe Civil Society found that effectiveness of a project majorly depends on honesty and transparency as proxy indicators for accountability. Beneficiaries from time to time call for NGOs to be more transparent and honest in delivering their objectives. Gibelman \& Gelman [14] support the ongoing argument in their study which emphasized the idea that the public has a right to know about charitable behavior and to demand a high degree of accountability especially in cases when NGOs receive donations from the public [15].

Customer feedback is important for any organization that would want to maintain a competitive advantage; therefore, organizations should put in place mechanisms that would enable them to get access to this feedback [16]. Conducting regular customer satisfaction surveys is one of the methods an organization can use to get feedback. This was confirmed by this study where it emerged as a key indicator of customer perspective measure of performance. The argument is strongly supported in the Management Decision Journal where Khalifa [17] comprehensively reviewed customer value as central to competitive advantage and long term success of business organizations.

\section{Conclusion}

The pre-conditions for qualifying a good predictor whereby an argument was based in the normality distribution pattern, revealed that service charter, response to customer needs, achievement of customer objectives, stakeholder participation in design, implementation and monitoring as well as regular customer survey qualified to be key factors in customer domain of NGO's performance measurement. This condition was not met by existence of customer related objectives, availability of ICT materials, value of honesty, courtesy and transparency necessitated cautious treatment the three latter factors as customer related performance measures.

In general, this study demonstrated the importance of customer focus as a management tool for NGO's top implementers. It highlights opinion of top managers on the beneficiary value perspectives during projects or programme's implementations. It therefore responds to the gap where most non-profit organizations leave out customer relevant accountability. However, it limits these thoughts to managers which may not reflect the true picture from the beneficiary. Accountability beneficiary where the beneficiary themselves are fully involved would be perspective to explore. The study further recommends putting more emphasis in regular beneficiary satisfaction surveys as this area is more likely to be ignored in the performance measurement evaluation.

\section{References}

[1] Kaplan, R. S. (2010). Conceptual Foundations of the Balanced Scorecard. [on-line], Boston, Harvard Business School Working Papers 10- 074, c 2010, [cit.: $18^{\text {th }}$ March, 2013].
[2] Hartnett, B., \& Matan, R. (2011). "The Balanced Scorecard: A Strategic Tool for the Nonprofit Sector" http://sobelcpa.com/sites/default/files/whitepaper.Jan2011\%20final.pdf (Accessed on 20/3/2013)

[3] Niven, P. R (2003). Adapting the Balanced Scorecard to fit the public and non-profit sectors, Primerus Consulting.

[4] Hassan, M. (2010) To what Extent Do The Legal Restrictions on NGOs in Egypt Undermine NGOS' Ability to Achieve Their Goals? MA Thesis the American University, Cairo http://www.hbs.edu/faculty/Publication\%20Files/10-074.pdf (Accessed on 22. 01.2016)

[5] Carman, J. G., \& Fredericks, K. A. (2008). Nonprofits and evaluation: Empirical evidence from the field. New Directions for Evaluation, 2008 (119): 51-71. doi: 10.1002/ev268.

[6] Fretchling, D. C. (2006). A balanced score card for managing strategy and measuring performance of destination management organizations. Faculty of Tiourism and Food, Dublin Institute of Technology, Ireland.

[7] Saunders, A., Wilson, B. (2001). Link between service charter and risk constraining incentives. Journal of Financial Services and Research, 19 (2): 185-195.

[8] Torrel, L. (2005). Service charter in relation to trust in government. Public Administration, 15 (6): 1540-6210.

[9] Gualandris, J., Klassen, R. D., Vachon, S. \& Kalchschmidt, M. (2015). Sustainable evaluation and verification in supply chains: Aligning and leveraging accountability to stakeholders. Journal of Operations Management, 38: 1-13

[10] Ken G Smith, Edwin A Locke (1990). Goal setting, planning, and organizational performance: An 'experimental simulation. Organizational Behavior and Human Decision Processes, 46 (1): 118-134.

[11] Sirawit Sirirak, Nazrul Islam, Do Ba Khang (2011). To investigate the influence of ICT on hotel performance in Thailand. Journal $\mathrm{f}$ hospitality and tourism technology, 2 (1): $34-49$.

[12] Asta, T. \& Rimantas, G. (2014). ICT impact on SMEs performance. Procedia-Social and behavioral sciences (110): 1218-1225.

[13] Ignatius, A. (2004). Fostering Accountability in Zimbabwe Civil Society. International Journal of Not-for Profit Law Vol. 6 (3): www.cnl.org//research/journal/Vol. 6 iss. 3/special_4 htm (Accessed on 1/5/2016).

[14] Gibelman, M \&Gelman, S. R. (2004). A loss of credibility: Pattern of wrong doing among NGOs. International Journal of Voluntary and Non-profit Organizations 15: 4, December 2004. DOI: 10.1007/s11266-004-1237-7.

[15] Murtaza, N \& Austin, M. (2011). Strategic Management of NGO's in Developing Countries. Journal of Nonprofit Education and Leadership, 2 (1): 7-30.

[16] Ranaweera, C., \& Prabhu, J. (2003). "On the relative importance of customer satisfaction and trust as determinants of customer retention and positive word of mouth". Journal of Targeting, Measurement and Analysis for Marketing, 12 (1), 82-90.

[17] Khalifa, S. A (2004). Customer value: a review of recent literature and an integrative configuration. Management Decision, 42 (5): 645-666. 